\title{
Frailty in people living with HIV
}

\author{
Mark Bloch*
}

\begin{abstract}
The life expectancy of people living with HIV (PLHIV) has dramatically improved with effective and well-tolerated antiretroviral therapy. This presents a new challenge in caring for this patient population, with up to $28 \%$ of older PLHIV being identified as frail. Studies suggest that the prevalence of frailty is higher in PLHIV compared to the general population, and that the onset of frailty occurs at an earlier age. Frail individuals often present with multiple and non-specific health complaints, fluctuating disability, falls and delirium, and are at higher risk for multiple adverse outcomes, post-operative complications, poor responses to vaccination and functional decline. They tend to require longer hospital admissions, are more likely to require nursing home care, and are at greater risk of mortality. The degree of frailty can fluctuate over time. Limited evidence exists to support the reversal of frailty, but epidemiological evidence suggests that interventions to assess and manage co-morbidities, reducing risk factors such as smoking, increasing exercise and optimising BMl, and improving personal and community resources, are all likely to reduce the risk of frailty. Physicians who care for PLHIV need to recognise and manage frailty in this patient population. This includes an understanding of: when to intervene aggressively in the management of an older patient with a new HIV diagnosis to delay or prevent permanent debility and frailty; when to acknowledge that the patient has become frail; and the role of geriatric medicine in addressing the specific issues and needs of this patient, such as maximising functional ability, preventing falls, reducing social isolation and improving quality of life.
\end{abstract}

Keywords: HIV, Frailty, Ageing, Comorbidities

\section{Background}

Due to the success of antiretroviral therapy (ART) in extending the lifespan of people living with HIV (PLHIV), and the reduction in incident HIV infections, the cohort of PLHIV has been gradually ageing and the median age is approaching 50 in most Western clinics [1]. As a result, frailty has increasingly become an issue of concern for those who manage patients with HIV.

Increasing evidence suggests that whilst PLHIV do not age prematurely, concerns regarding frailty normally seen in a geriatric population can often be observed in patients with HIV a decade or more earlier [2, 3]. In addition, the prevalence of comorbidities, multi-morbidity and frailty is higher in PLHIV than the general population at all ages, and the gap between the two populations widens with age [4-6].

*Correspondence: mark.bloch@holdsworthhouse.com.au Holdsworth House Medical Practice, Darlinghurst, Level 3, 26 College St, Sydney, NSW 2010, Australia
Several factors predispose PLHIV to higher rates of frailty, including the effects of chronic inflammation from HIV (even with complete plasma virological suppression), the toxic effects of earlier antiretroviral regimens, delayed initiation of therapy for HIV, higher rates of multi-morbidity (the presence of two or more chronic medical conditions) and co-infection, HIV-associated neurocognitive disorder, lifestyle factors such as smoking, and poverty and social isolation [7].

\section{Definition of frailty}

There is redundancy in living systems that allows for loss of function that can be compensated for, which can be measured by deficit accumulation. Accumulation of deficits over time predisposes an individual to the development of frailty [8]. Frailty has been defined as an increased vulnerability to stressors due to a lack of reserve and reduced ability to compensate for disruptions to homeostasis [8]. Frailty demonstrates that biological age may vary at the same chronological age.

There are 3 different ways of defining frailty: 
1. As a clinical syndrome or phenotype, defined by Fried et al. [9].

2. Through the subjective opinion of the clinician.

3. Using multidimensional risk state or frailty index (FI) $[10,11]$.

\section{Fried phenotype of frailty}

The Fried phenotype of frailty is defined as three or more of five parameters: [9].

1. Unintentional weight loss of more than $10 \mathrm{lbs}$ in the previous year.

2. Self-reported exhaustion.

3. Weak grip strength.

4. Slow walking speed.

5. Reduced physical activity.

Patients with one or two of these characteristics are classified as 'pre-frail' [9].

The Fried definition of frailty has clinical coherency and reproducibility, and includes sarcopenia and its pathophysiological manifestations in its characterisation of frailty. However, it doesn't account for neurocognitive and psychosocial aspects of frailty and relies on performance-based tests [9].

\section{Subjective opinion}

Subjective assessment of biological age and frailty that considers appearance, mobility and communication can have a good inter-rater correlation [12]. A seven-stage clinical frailty scale ranging from very fit to severely frail was established by Rockwood et al. and this correlated with outcomes of institutionalisation and survival [13]. These subjective assessments have limited generalisability and depend on the training, and geriatric experience and expertise of the observer.

\section{Frailty index}

The FI developed by Rockwood and Mitnitski is based on the concept of frailty as an accumulation of deficits [10]. The quantity of deficits that accumulate over a person's lifetime can be scored and higher numbers are associated with increasing likelihood of frailty. The deficits include defined symptoms, signs, diseases, disabilities and laboratory markers [10]. Deficits accumulate with age, are associated with adverse outcomes, occur across different domains, and can be measured over time [11].

FI figures correlate closely across countries, accumulate at a rate of approximately $3 \%$ per annum in the community, and are strongly correlated with mortality [14]. Ageing-associated adverse outcomes of decreased quality of life, increased hospitalisation and risk of death correlate more closely with the FI than with the phenotypic characterisation of frailty [15] or with chronological age [16].

\section{Pathophysiology of frailty}

Frailty is associated with inflammation. It is unclear whether inflammation drives frailty, is a compensatory mechanism that occurs with frailty, or is an epiphenomenon [17]. A number of immunological and physiological impairments combine to increase the risk of frailty. Ongoing inflammation is a feature of HIV infection, despite plasma virological suppression with ART [18, 19]. A number of immunological and pathophysiological impairments that are found in ageing are also found in those with chronic HIV infection and combine to increase the risk of frailty $[18,19]$.

The immunological features of ageing and frailty consist of immunosenescence, immune activation and increased levels of circulating cytokines (C-reactive protein [CRP], tumour necrosis factor alpha [TNF- $\alpha$ ], interleukin-6 [IL-6]) $[20,21]$. Chronic cytomegalovirus (CMV) infection, which is common in PLHIV, may cause clonal expansion leading to immunosenescence, as well as causing immune activation and inflammation [22]. The role of chronic CMV in frailty has not been determined.

Physiological dysregulation associated with frailty was identified in the Women's Health in Ageing Studies I and II (WHAS). Anaemia, inflammation, insulin-like growth factor-1 (IGF-1), dehydroepiandrosterone-sulphate (DHEA-S), haemoglobin A1c (HbA1c), micronutrients, adiposity and fine-motor speed were associated with a non-linear increase in frailty [23].

Mitochondrial loss from telomere shortening with ageing [24], and the effects of nucleoside analogue antiretrovirals used in the treatment of HIV [25], may also contribute to frailty by causing sarcopenia. Polypharmacy is also associated with a higher frailty risk in older people [26].

\section{Characteristics of and risk factors for frailty}

Frail individuals often present with multiple and nonspecific health complaints, fluctuating disability, falls and delirium, and are at higher risk for multiple adverse outcomes, including post-operative complications, poor responses to vaccination and functional decline. They tend to require longer hospital admissions, are more likely to require nursing home care, and are at greater risk of mortality [8].

Known risk factors for frailty include chronic kidney disease [27], cerebrovascular disease [28], cardiovascular disease [29] and smoking [30,31], while increased exercise has a protective association with frailty [32]. Risk for frailty increases at both high and low BMI-those with BMI between 25 and 29.9 had the lowest FI scores and 
lowest prevalence of Fried frailty [33]. Social factors such as personal wealth and neighbourhood resources also impact frailty risk [34], and those with frailty in lowerincome countries that have fewer resources have substantially higher rates of mortality [35].

HIV infection has also been associated with frailty using the Fried phenotype and FI [36, 37].

\section{Frailty in the HIV setting}

Large, observational cohorts of HIV patients that measure ART use, clinical progress and development of co-morbidities have been useful in understanding associations with HIV infection, including the association between HIV and frailty.

The multicenter AIDS cohort study (MACS) defined frailty as three of: unplanned weight loss; exhaustion; low physical activity level; and slow walking speed. The study found that $4-10 \%$ of patients with HIV were frail, including up to $50 \%$ of patients over the age of 50 [5]. In the pre-ART era, there was a 10 -fold increase in frailty in PLHIV compared to an HIV-negative population, but the prevalence of frailty in PLHIV halved with the introduction and use of ART [5]. In addition, low CD4+ T cell count and high HIV plasma RNA were associated with increased risk of frailty [5].

In the AGEhIV cohort study, PLHIV had a higher prevalence of frailty compared to HIV-negative individuals at all ages [6].

Frailty indexes specific to PLHIV have been established. The veterans ageing cohort study (VACS) developed a proxy FI that includes CD4+ T cell count, HIV viral load, hepatitis $\mathrm{C}$ co-infection, hepatic, renal and haematological markers, as well as D-dimer and soluble CD14, with the aim of predicting a mortality risk index in PLHIV [38]. The Modena HIV Metabolic Clinic developed a 37-item FI that includes HIV-related parameters to assess patients, and it has been found to be associated with multi-morbidity [39].

Higher rates of many co-morbidities that are associated with frailty occur in PLHIV compared to the general population, even adjusting for risk factors [40]. These co-morbidities include cardiovascular disease, metabolic disease, liver and kidney disease, osteoporosis and cancers. Frailty in PLHIV has been associated with increased falls, poorer functioning, decreased self-care, poor quality of life and depression, and neurocognitive impairment [41-44].

In addition to differences caused by constitution and other co-morbidities, there may also be differences in the risk of developing frailty between older patients with recently acquired HIV, patients with chronic HIV infection effectively suppressed on therapy, and patients with late diagnosis, untreated chronic HIV.

\section{Managing frailty in patients with HIV}

Those treating HIV have become much more skilled in recognising and managing co-morbidity in PLHIV. There is now a need for further training so that HIV caregivers are equipped to recognise and manage ageing and frailty in this patient population as well.

Facilities for caring for those ageing with HIV, as well as those who have become frail, are currently quite variable in the levels of acceptance and comfort, and the ability to manage stigma and discrimination.

When managing frailty in PLHIV, physicians need to understand: when to intervene aggressively in the management of an older patient with a new HIV diagnosis to delay or prevent permanent debility and frailty; when to acknowledge that the patient has become frail; and the role of geriatric medicine in addressing the specific issues and needs of this patient such as maximising functional ability, preventing falls, reducing social isolation, and improving quality of life. The degree of frailty can fluctuate over time, which can complicate assessment of a patient.

There is a paucity of randomised clinical trial data on reversing frailty once it has been established. In the frailty interventions trial in elderly subjects (FITNESS) randomised controlled trial, simple measures such as randomised vitamin $\mathrm{D}$ supplementation and exercise over 10 weeks did not demonstrate improvements in self-reported physical health, physical performance, social activities or mental health [45].

A randomised multidisciplinary intervention over 12 months did significantly reduce frailty criteria and increased stability compared to controls, but did not impact on hospital admission, institutionalisation and death [46]. However, with 216 community participants, it was likely not powered to demonstrate these end points.

The comprehensive geriatric assessment (CGA) has been shown to be useful in managing elderly patients [47] and may be of benefit in patients with HIV with suspected frailty, even if they are below the usual geriatric age of 75 years.

There is variability in the evidence surrounding interventions that prevent frailty [48]. Epidemiological evidence suggests that interventions to assess and manage co-morbidities, reducing risk factors such as smoking, increasing exercise and optimising BMI, and improving personal and community resources, may reduce the risk of frailty [30-34].

In patients with HIV, managing frailty is likely to require early introduction of newer ART to maintain $\mathrm{CD} 4+\mathrm{T}$ cell count, together with lifestyle interventions and proactive management, to reduce the risk of co-morbidities. 


\section{Forum presentations}

This report summarises presentations from the 2017 HIV innovation forum. Full speaker presentations can be accessed at http://www.innovationforum2017.com.au (password: HIVinnovation).

\begin{abstract}
Abbreviations
ART: antiretroviral therapy; CGA: comprehensive geriatric assessment; CMV: cytomegalovirus; CRP: C-reactive protein; DHEA-S: dehydroepiandrosteronesulphate; Fl: frailty index; FITNESS: frailty interventions trial in elderly subjects; HbA1c: haemoglobin A1C; IGF-1: insulin-like growth factor-1; IL-6: interleukin-6; MACS: multicenter AIDS cohort study; TNF-a: tumour necrosis factor alpha; VACS: veterans ageing cohort study.
\end{abstract}

\section{Authors' contributions}

MB wrote the first draft of the manuscript. A medical writer assisted with editing and formatting the manuscript. The author read and approved the final manuscript.

\section{Acknowledgements}

The author thanks Associate Professor Ruth Hubbard for providing guidance and recommendations for this manuscript.

\section{Competing interests}

$M B$ has received funding to his institution for clinical research from Gilead Sciences, ViiV Healthcare, Merck Sharp \& Dohme (MSD), Bristol Myer-Squibb, Amgen, Novartis. MB has received funding for medical advisory boards or education and lecturing from Gilead Sciences, ViiV Healthcare, MSD, Bristol Myers-Squibb, Abbvie. MB has received funding for travel to scientific meetings from Gilead Sciences.

\section{Availability of data and materials \\ Not applicable.}

\section{Consent for publication}

Not applicable.

\section{Ethics approval and consent to participate}

Not applicable.

\section{Funding}

This work was supported by Gilead Sciences. Gilead had no role in data collection, analysis or interpretation, and were not involved in the writing of this manuscript.

\section{Publisher's Note}

Springer Nature remains neutral with regard to jurisdictional claims in published maps and institutional affiliations.

Received: 9 July 2018 Accepted: 9 November 2018

Published online: 16 November 2018

\section{References}

1. Sabin CA, Reiss P. Epidemiology of ageing with HIV: what can we learn from cohorts? AIDS. 2017;31(Suppl 2):S121-8.

2. Rasmussen LD, May MT, Kronborg G, Larsen CS, Pedersen C, Gerstoft J, et al. Time trends for risk of severe age-related diseases in individuals with and without HIV infection in Denmark: a nationwide population-based cohort study. Lancet HIV. 2015;2:e288-98.

3. Önen NF, Agbebi A, Shacham E, Stamm KE, Önen AR, Overton ET. Frailty among HIV-infected persons in an urban outpatient care setting. J Inf. 2009;59:346-52.

4. Petoumenos K, Huang R, Hoy J, Bloch M, Templeton DJ, Baker D, Giles M, Law MG, Cooper DA. Prevalence of self-reported comorbidities in HIV positive and HIV negative men who have sex with men over 55 yearsthe Australian positive \& peers longevity evaluation study (APPLES). PLoS ONE. 2017;12:e0184583.

5. Desquilbet L, Margolick JB, Fried LP, Phair JP, Jamieson BD, Holloway M, Jacobson LP, Multicenter ACS. Relationship between a frailty-related phenotype and progressive deterioration of the immune system in HIVinfected men. J Acquir Immune Defic Syndr. 2009;50:299-306.

6. Kooij KW, Wit FW, Schouten J, van der Valk M, Godfried MH, Stolte IG, Prins $M$, Falutz J, Reiss P, Group AGCS. HIV infection is independently associated with frailty in middle-aged HIV type 1-infected individuals compared with similar but uninfected controls. AIDS. 2016;30:241-50.

7. Willig AL, Overton ET, Saag MS. The silent epidemic — frailty and aging with HIV. Total Patient Care HIV HCV. 2016;1:6-17.

8. Clegg A, Young J, lliffe S, Rikkert MO, Rockwood K. Frailty in elderly people. Lancet. 2013;381:752-62.

9. Fried LP, Tangen CM, Walston J, Newman AB, Hirsch C, Gottdiener J, Seeman T, Tracy R, Kop WJ, Burke G, et al. Frailty in older adults: evidence for a phenotype. J Gerontol A Biol Sci Med Sci. 2001;56:M146-56.

10. Mitnitski AB, Mogilner AJ, Rockwood K. Accumulation of deficits as a proxy measure of aging. Sci World J. 2001;1:323-36.

11. Searle SD, Mitnitski A, Gahbauer EA, Gill TM, Rockwood K. A standard procedure for creating a frailty index. BMC Geriatr. 2008;8:24.

12. Olde Rikkert MG. Visual estimation of biological age of elderly subjects: good interrater agreement. Gerontology. 1999;45:165-7.

13. Rockwood K, Song X, MacKnight C, Bergman H, Hogan DB, McDowell I, Mitnitski A. A global clinical measure of fitness and frailty in elderly people. CMAJ. 2005;173:489-95.

14. Mitnitski A, Song X, Skoog I, Broe GA, Cox JL, Grunfeld E, Rockwood K. Relative fitness and frailty of elderly men and women in developed countries and their relationship with mortality. J Am Geriatr Soc. 2005;53:2184-9.

15. Kulminski A, Yashin A, Arbeev K, Akushevich I, Ukraintseva S, Land K, Manton K. Cumulative index of health disorders as an indicator of agingassociated processes in the elderly: results from analyses of the national long term care survey. Mech Ageing Dev. 2007;128:250-8.

16. Romero-Ortuno $R$. The frailty instrument for primary care of the survey of health, ageing and retirement in Europe predicts mortality similarly to a frailty index based on comprehensive geriatric assessment. Geriatr Gerontol Int. 2013;13:497-504.

17. Hubbard RE, Woodhouse KW. Frailty, inflammation and the elderly. Biogerontology. 2010;11:635-41.

18. Deeks SG. HIV infection, inflammation, immunosenescence, and aging. Annu Rev Med. 2011;62:141-55.

19. Hunt PW. HIV and ageing: emerging research issues. Curr Opin HIV AIDS. 2014;9:302-8

20. Hubbard RE, O'Mahony MS, Calver BL, Woodhouse KW. Plasma esterases and inflammation in ageing and frailty. Eur J Clin Pharmacol. 2008;64:895-900

21. Li H, Manwani B, Leng SX. Frailty, inflammation, and immunity. Aging Dis. 2011;2:466-73.

22. Tu W, Rao S. Mechanisms underlying T cell immunosenescence: aging and cytomegalovirus infection. Front Microbiol. 2016;7:2111.

23. Fried LP, Xue QL, Cappola AR, Ferrucci L, Chaves P, Varadhan R, Guralnik JM, Leng SX, Semba RD, Walston JD, et al. Nonlinear multisystem physiological dysregulation associated with frailty in older women: implications for etiology and treatment. J Gerontol A Biol Sci Med Sci. 2009;64:1049-57.

24. Sahin E, Depinho RA. Linking functional decline of telomeres, mitochondria and stem cells during ageing. Nature. 2010;464:520-8.

25. Leeansyah E, Cameron PU, Solomon A, Tennakoon S, Velayudham P, Gouillou M, Spelman T, Hearps A, Fairley C, de Smit V, et al. Inhibition of telomerase activity by human immunodeficiency virus (HIV) nucleos(t) ide reverse transcriptase inhibitors: a potential factor contributing to HIVassociated accelerated aging. J Infect Dis. 2013;207:1157-65.

26. Veronese N, Stubbs B, Noale M, Solmi M, Pilotto A, Vaona A, Demurtas J, Mueller C, Huntley J, Crepaldi G, Maggi S. polypharmacy is associated with higher frailty risk in older people: an 8-year longitudinal cohort study. J Am Med Dir Assoc. 2017;18:624-8.

27. Chowdhury R, Peel NM, Krosch M, Hubbard RE. Frailty and chronic kidney disease: a systematic review. Arch Gerontol Geriatr. 2017;68:135-42. 
28. Veronese N, Sigeirsdottir K, Eiriksdottir G, Marques EA, Chalhoub D, Phillips CL, Launer $\sqcup$, Maggi S, Gudnason V, Harris TB, Frailty and Risk of Cardiovascular Diseases in Older Persons. The age, gene/environment susceptibility-reykjavik study. Rejuven Res. 2017;20:517-24.

29. Newman AB, Gottdiener JS, McBurnie MA, Hirsch CH, Kop WJ, Tracy R, Walston JD, Fried LP, Cardiovascular Health Study Research G. Associations of subclinical cardiovascular disease with frailty. J Gerontol A Biol Sci Med Sci. 2001;56:M158-66.

30. Hubbard RE, Searle SD, Mitnitski A, Rockwood K. Effect of smoking on the accumulation of deficits, frailty and survival in older adults: a secondary analysis from the Canadian Study of Health and Aging. J Nutr Health Aging. 2009;13:468-72.

31. Kojima G, lliffe S, Walters K. Smoking as a predictor of frailty: a systematic review. BMC Geriatr. 2015;15:131.

32. Hubbard RE, Fallah N, Searle SD, Mitnitski A, Rockwood K. Impact of exercise in community-dwelling older adults. PLoS ONE. 2009;4:e6174.

33. Hubbard RE, Lang IA, Llewellyn DJ, Rockwood K. Frailty, body mass index, and abdominal obesity in older people. J Gerontol A Biol Sci Med Sci. 2010;65:377-81.

34. Lang IA, Hubbard RE, Andrew MK, Llewellyn DJ, Melzer D, Rockwood K. Neighborhood deprivation, individual socioeconomic status, and frailty in older adults. J Am Geriatr Soc. 2009;57:1776-80.

35. Theou O, Brothers TD, Rockwood MR, Haardt D, Mitnitski A, Rockwood $K$. Exploring the relationship between national economic indicators and relative fitness and frailty in middle-aged and older Europeans. Age Ageing. 2013:42:614-9.

36. Brothers TD, Kirkland S, Theou O, Zona S, Malagoli A, Wallace LMK, Stentarelli C, Mussini C, Falutz J, Guaraldi G, Rockwood K. Predictors of transitions in frailty severity and mortality among people aging with HIV. PLOS ONE. 2017;12:e0185352.

37. Onen NF, Agbebi A, Shacham E, Stamm KE, Onen AR, Overton ET. Frailty among HIV-infected persons in an urban outpatient care setting. J Infect. 2009:59:346-52.

38. Tate JP, Justice AC, Hughes MD, Bonnet F, Reiss P, Mocroft A, Nattermann J, Lampe FC, Bucher HC, Sterling TR, et al. An internationally generalizable risk index for mortality after one year of antiretroviral therapy. AIDS. 2013;27:563-72.

39. Guaraldi G, Brothers TD, Zona S, Stentarelli C, Carli F, Malagoli A, Santoro A, Menozzi M, Mussi C, et al. A frailty index predicts survival and incident multimorbidity independent of markers of HIV disease severity. AIDS. 2015;29:1633-41.

40. Guaraldi G, Orlando G, Zona S, Menozzi M, Carli F, Garlassi E, Berti A, Rossi E, Roverato A, Palella F. Premature age-related comorbidities among HIVinfected persons compared with the general population. Clin Infect Dis. 2011;53:1120-6.

41. Branas F, Jimenez Z, Sanchez-Conde M, Dronda F, Lopez-Bernaldo De Quiros JC, Perez-Elias MJ, Miralles P, Ramirez M, Moreno A, Berenguer J, Moreno S. Frailty and physical function in older HIV-infected adults. Age Ageing. 2017:46:522-6.

42. Brothers TD, Kirkland S, Guaraldi G, Falutz J, Theou O, Johnston BL, Rockwood K. Frailty in people aging with human immunodeficiency virus (HIV) infection. J Infect Dis. 2014;210:1170-9.

43. Guaraldi G, Malagoli A, Theou O, Brothers TD, Wallace L, Torelli R, Mussini C, Sartini S, Kirkland SA, Rockwood K. Correlates of frailty phenotype and frailty index and their associations with clinical outcomes. HIV Med. 2017;18:764-71.

44. Zamudio-Rodriguez A, Belaunzaran-Zamudio PF, Sierra-Madero J, Cuellar-Rodriguez JM, Crabtree-Ramirez B, Alcala-Zermeno JL, Amieva H, Avila-Funes JA. Association between frailty and HIV-associated neurodegenerative disorders among older adults living with HIV. AIDS Res Hum Retroviruses. 2018;34(5):449-55.

45. Latham NK, Anderson CS, Lee A, Bennett DA, Moseley A, Cameron ID, Fitness Collaborative G. A randomized, controlled trial of quadriceps resistance exercise and vitamin $D$ in frail older people: the frailty interventions trial in elderly subjects (FITNESS). J Am Geriatr Soc. 2003;51:291-9.

46. Cameron ID, Fairhall N, Langron C, Lockwood K, Monaghan N, Aggar C, Sherrington C, Lord SR, Kurrle SE. A multifactorial interdisciplinary intervention reduces frailty in older people: randomized trial. BMC Med. 2013;11:65

47. Ellis $G$, Langhorne P. Comprehensive geriatric assessment for older hospital patients. Br Med Bull. 2004;71:45-59.

48. Puts MTE, Toubasi S, Andrew MK, Ashe MC, Ploeg J, Atkinson E, Ayala AP, Roy A, Rodriguez Monforte M, Bergman H, McGilton K. Interventions to prevent or reduce the level of frailty in community-dwelling older adults: a scoping review of the literature and international policies. Age Ageing. 2017:46:383-92.
Ready to submit your research? Choose BMC and benefit from:

- fast, convenient online submission

- thorough peer review by experienced researchers in your field

- rapid publication on acceptance

- support for research data, including large and complex data types

- gold Open Access which fosters wider collaboration and increased citations

- maximum visibility for your research: over $100 \mathrm{M}$ website views per year

At $\mathrm{BMC}$, research is always in progress.

Learn more biomedcentral.com/submissions 